\title{
Development of a cardiac surgery simulation curriculum: From needs assessment results to practical implementation
}

\author{
Craig J. Baker, MD, FACS, Raina Sinha, MD, MPH, and Maura E. Sullivan, MSN, PhD
}

Objective: A paradigm shift in surgical training has led to national efforts to incorporate simulation-based learning into cardiothoracic residency programs. Our goal was to determine the feasibility of developing a cardiac surgery simulation curriculum using the formal steps of curriculum development.

\begin{abstract}
Methods: Cardiothoracic surgery residents $(n=6)$ and faculty $(n=9)$ evaluated 54 common cardiac surgical procedures to determine their need for simulation. The highest scoring procedures were grouped into similarly themed monthly modules, each with specific learning objectives. Educational tools consisting of inanimate, animate, and cadaveric facilities and a newly created virtual operating room were used for curriculum implementation. Resident satisfaction was evaluated by way of a 5-point Likert scale. Perceived competency (scale of 1-10) and pre-/post-self-confidence (scale of 1-5) scores were collected and analyzed using cumulative mean values and a paired $t$-test.
\end{abstract}

Results: Of the 23 highest scoring procedures (mean score, $\geq 4.0$ ) on the needs assessment, 21 were used for curriculum development. These procedures were categorized into 12 monthly modules. The simulation curriculum was implemented using the optimal simulation tool available. Resident satisfaction $(n=57)$ showed an overwhelmingly positive response (mean score, $\geq 4.7$ ). The perceived competency scores highlighted the procedures residents were uncomfortable performing independently. The pre-/post-self-confidence scores increased throughout the modules, and the differences were statistically significant $(P<.001)$.

Conclusions: It is feasible to develop and implement a cardiac surgery simulation curriculum using a structured approach. High-fidelity, low-technology tools such as a fresh tissue cadaver laboratory and a virtual operating room could be important adjuncts. (J Thorac Cardiovasc Surg 2012;144:7-16)

There has been a paradigm shift in the training of surgical residents from the traditional "apprenticeship" model to a hybrid one ${ }^{1}$ involving simulation training. This shift is in response to several current challenges in residency training, including time constraints, patient safety concerns, financial costs, and decreasing lengths of training programs. Currently, an average of 8.3 years of training after medical school, including 5 years or more of general surgery training and 2 to 3 years of specialized training, are required to become a cardiothoracic (CT) surgeon. ${ }^{2} \mathrm{An}$ anticipated shortage of CT surgeons by 2020 and $30 \%$ to $40 \%$ vacant spots in the Accreditation Council for Graduate Medical Education-approved CT residency programs in the past few years has contributed in part to the development

\footnotetext{
From the Department of Surgery, University of Southern California Keck School of Medicine, Los Angeles, Calif.

This project was supported by a grant from the Heart and Lung Surgery Foundation, Los Angeles, Calif.

Disclosures: Authors have nothing to disclose with regard to commercial support. Read at the 37th Annual Meeting of The Western Thoracic Surgical Association, Colorado Springs, Colorado, June 22-25, 2011

Received for publication June 20, 2011; revisions received Nov 28, 2011; accepted for publication March 12, 2012; available ahead of print April 16, 2012.

Address for reprints: Craig J. Baker, MD, FACS, Division of Cardiothoracic Surgery, Department of Surgery, Cardiovascular Thoracic Institute, University of Southern California Keck School of Medicine, 1520 San Pablo St, Suite 4300, Los Angeles, CA 90033 (E-mail: cbaker@surgery.usc.edu).

$0022-5223 / \$ 36.00$

Copyright (c) 2012 by The American Association for Thoracic Surgery doi:10.1016/j.jtcvs.2012.03.026
}

of an integrated 6-year training program. It has been proposed that all Accreditation Council for Graduate Medical Education-approved CT residency programs adopt this training platform. It is important to remember that with the new training platform, a transition will occur to younger, less-experienced learners who will begin CT residency with decreased skills compared with the traditional graduate of a 5-year general surgery training program.

The utility of simulation has been well documented in graduate medical education ${ }^{3}$ and is based on the concept of "deliberate practice." ${ }^{\text {B }}$ Because the operating room affords little time for "practice and reflection" in surgery owing to patient safety and ethical concerns, simulation can provide the necessary training in the laboratory. This concept is especially valid in technically challenging fields such as CT surgery and was strongly embraced at the Visioning Simulation in Cardiothoracic Surgery Conference in April 2007 (Cambridge, Mass). National efforts are currently underway involving the Thoracic Surgery Directors' Association, Joint Council of Thoracic Surgery Education, American Board of Thoracic Surgery, and Thoracic Surgery Foundation for Research and Education to incorporate simulation-based training into the CT residency. The Joint Council of Thoracic Surgery Education, in conjunction with the Thoracic Surgery Directors' Association, has sponsored an annual "Boot Camp" at the University of North Carolina since 2008, allowing approximately one third of 


\author{
Abbreviations and Acronyms \\ $\mathrm{CT}=$ cardiothoracic \\ LAC $=$ Los Angeles County \\ USC $=$ University of Southern California
}

all first-year CT surgical residents to participate in facultysupervised simulation workshops. ${ }^{5}$

Several studies have validated the need for simulation in cardiac surgery ${ }^{5-10}$ and various simulation tools currently exist, including those built by Fann and colleagues, ${ }^{6}$ Ramphal and colleagues, ${ }^{7}$ and Schiralli and colleagues, ${ }^{8}$ that simulate standard and beating-heart coronary anastomosis, valvular cardiac surgery, and cannulation for cardiopulmonary bypass. Although simulation centers have emerged during the past few decades and offer a dedicated place to practice and hone skills in a structured and stress-free environment, many centers rely on an opportune approach to module development and lack an organized approach to curriculum development. In addition, models for teaching other intricate skills such as internal mammary artery harvesting and performance of redo sternotomy in the laboratory are nonexistent. The true benefit of simulation training in cardiac surgery will occur only when training programs develop and integrate regularly scheduled simulation sessions in the context of established curricula. A comprehensive skills curriculum could help to ensure that residents are equipped with the basic skills through a clearly defined and cohesive program and might reduce gaps and duplication in the curricula. However, widespread adoption and penetration into individual training programs is lacking, and no standardized approach for developing a simulation based curriculum exists. The challenges to overcome in this process include the ability to reach agreement among faculty and residents regarding which skills are essential for inclusion and the feasibility and acceptability for all residents and faculty at 1 institution.

The goal of our study was to apply the steps of formal curriculum development to develop and implement a comprehensive cardiac surgery curriculum. The specific aims included determining which skills are the most important to include in a cardiac simulation curriculum at our institution, developing and implementing a structured simulation curriculum, assessing the effect of the curriculum on residents' self-efficacy for each skill, and evaluating the feasibility and acceptability of a simulation-based curriculum by faculty and residents.

\section{METHODS}

\section{Curriculum Development}

The steps of formal curriculum development as outlined by Kern and colleagues ${ }^{11}$ are (1) problem identification, (2) needs assessment, (3) goals and objectives, (4) educational methods, (5) curriculum implementation, (6) evaluation, and (7) maintenance.

\section{Needs Assessment}

A list of 54 cardiac surgical procedures commonly performed during residency training was compiled by a core group of CT faculty and educators in the Department of Surgery at the University of Southern California (USC). The skills were categorized into 4 groups: general cardiac surgery, ischemic heart disease, heart valve disease, and thoracic aortic disease. The CT surgery residents $(n=6)$ and faculty members $(n=9)$ were surveyed and instructed to rank each skill on a scale of 1 to 5, with 1 the least and 5, the most important to simulate in the laboratory (Table 1). The data from the needs assessment survey were entered into standard Excel format and mean scores were calculated.

\section{Goals and Objectives}

The highest scoring procedures from the combined resident and faculty needs assessment survey results were grouped into defined modules that could be incorporated into our existing cardiac surgery educational curriculum. The learning objectives were subsequently created for each module and consisted of both broad educational objectives and specific measurable objectives. In curriculum development, the broad educational objectives serve as the overall goal of the curriculum, and the specific measurable objectives serve to direct the choice of curricular content, determine which learning methods would be the most effective and enable evaluation of the students and the curriculum. ${ }^{11}$ The learning objectives were determined by a subgroup of faculty who reviewed each topic and determined the priorities and goals for each session.

\section{Educational Methods}

Inanimate, animate, and cadaveric models at the USC Surgical Skills Training and Education Center were available to teach the simulation modules. Each module was assessed in regard to the optimal available simulation method to capitalize on our learning objectives. The inanimate models were composed of anastomotic portable task trainers with synthetic target vessels (Chamberlain Group, Great Barrington, Mass) as described by Fann and colleagues, ${ }^{6}$ as well as commercially available aortic, mitral, and saphenous vein trainers (Chamberlain Group). The animate models consisted of wet-laboratory porcine heart preparations in conjunction with commercially available cardiac surgery products (valves, annuloplasty rings, ablation tools, and so forth).

Several of the sessions were held in the Fresh Tissue Dissection Laboratory. This cadaveric simulation center was established through a unique relationship with the Department of Health Services in Los Angeles County (LAC) and the Office of Decedent Affairs at LAC+USC Medical Center, where unclaimed cadavers are donated (free of charge) to the faculty and staff at the LAC+USC Medical Center when used for educational purposes. The cadavers used in this laboratory are fresh and lightly conditioned $^{12}$ and provide the opportunity for a realistic technical surgical experience.

In addition, a high-fidelity simulator modeled after the Ramphal simulator ${ }^{7}$ was developed to create a realistic operative experience and establish simulation for cardiopulmonary bypass. This simulator uses a porcine beating heart model to allow teaching and assessment of skills from cardiac cannulation through the operative procedure to successful weaning in a simulated operating room environment.

\section{Curriculum Implementation}

Cardiac surgery simulation modules were incorporated into the existing cardiac surgery educational curriculum. On the fourth Friday of each month, our regular 2-hour educational didactic core curriculum was replaced with a focused simulation laboratory. One monthly session was dedicated to each module, and all CT residents were required to attend. The residents were graduates of traditional 5-year general surgery residencies and included first-, second-, and third-year cardiac surgery residents. Each 2-hour session was staffed by 3 to 4 CT faculty members who were 
TABLE 1. Cardiothoracic surgery procedural skills needs assessment survey

\begin{tabular}{|c|c|c|c|c|c|}
\hline \multirow{2}{*}{$\frac{\text { Skill }}{\text { General cardiac surgery }}$} & \multicolumn{2}{|c|}{ Not necessary } & \multicolumn{2}{|c|}{ Helpful } & \multirow[t]{2}{*}{ Essential } \\
\hline & & & & & \\
\hline Median sternotomy & 1 & 2 & 3 & 4 & 5 \\
\hline Redo sternotomy & 1 & 2 & 3 & 4 & 5 \\
\hline Aortic cannulation & 1 & 2 & 3 & 4 & 5 \\
\hline Venous cannulation & 1 & 2 & 3 & 4 & 5 \\
\hline $\begin{array}{l}\text { Cardioplegia cannula } \\
\text { placement }\end{array}$ & 1 & 2 & 3 & 4 & 5 \\
\hline $\begin{array}{l}\text { Femoral cannulation/ } \\
\text { decannulation }\end{array}$ & 1 & 2 & 3 & 4 & 5 \\
\hline Coronary sinus catheterization & 1 & 2 & 3 & 4 & 5 \\
\hline Placement of vent & 1 & 2 & 3 & 4 & 5 \\
\hline Beginning CPB & 1 & 2 & 3 & 4 & 5 \\
\hline Weaning from $\mathrm{CPB}$ & 1 & 2 & 3 & 4 & 5 \\
\hline $\begin{array}{l}\text { Intra-aortic balloon pump } \\
\text { placement }\end{array}$ & 1 & 2 & 3 & 4 & 5 \\
\hline Pericardial window & 1 & 2 & 3 & 4 & 5 \\
\hline \multicolumn{6}{|l|}{ Ischemic heart disease } \\
\hline Open saphenous vein harvest & 1 & 2 & 3 & 4 & 5 \\
\hline $\begin{array}{l}\text { Endoscopic saphenous vein } \\
\text { harvest }\end{array}$ & 1 & 2 & 3 & 4 & 5 \\
\hline Open radial artery harvest & 1 & 2 & 3 & 4 & 5 \\
\hline $\begin{array}{l}\text { Endoscopic radial artery } \\
\text { harvest }\end{array}$ & 1 & 2 & 3 & 4 & 5 \\
\hline IMA harvest & 1 & 2 & 3 & 4 & 5 \\
\hline Coronary artery anastomosis & 1 & 2 & 3 & 4 & 5 \\
\hline $\begin{array}{l}\text { Beating heart coronary } \\
\text { anastomosis }\end{array}$ & 1 & 2 & 3 & 4 & 5 \\
\hline $\begin{array}{l}\text { Minimally invasive direct } \\
\text { coronary artery bypass }\end{array}$ & 1 & 2 & 3 & 4 & 5 \\
\hline Proximal anastomosis & 1 & 2 & 3 & 4 & 5 \\
\hline Repair of postinfarct VSD & 1 & 2 & 3 & 4 & 5 \\
\hline $\begin{array}{l}\text { Transmyocardial } \\
\text { revascularization }\end{array}$ & 1 & 2 & 3 & 4 & 5 \\
\hline \multicolumn{6}{|l|}{ Heart valve disease } \\
\hline Aortic valve replacement & 1 & 2 & 3 & 4 & 5 \\
\hline $\begin{array}{l}\text { Management of small aortic } \\
\text { root }\end{array}$ & 1 & 2 & 3 & 4 & 5 \\
\hline Aortic root replacement & 1 & 2 & 3 & 4 & 5 \\
\hline Aortic homograft & 1 & 2 & 3 & 4 & 5 \\
\hline Ross procedure & 1 & 2 & 3 & 4 & 5 \\
\hline $\begin{array}{l}\text { Valve-sparing aortic root } \\
\text { replacement }\end{array}$ & 1 & 2 & 3 & 4 & 5 \\
\hline Mitral valve replacement & 1 & 2 & 3 & 4 & 5 \\
\hline $\begin{array}{l}\text { Mitral valve posterior leaflet } \\
\text { repair }\end{array}$ & 1 & 2 & 3 & 4 & 5 \\
\hline $\begin{array}{l}\text { Mitral valve anterior leaflet } \\
\text { repair }\end{array}$ & 1 & 2 & 3 & 4 & 5 \\
\hline Minimally invasive AVR & 1 & 2 & 3 & 4 & 5 \\
\hline Minimally invasive MVR & 1 & 2 & 3 & 4 & 5 \\
\hline Tricuspid valve repair & 1 & 2 & 3 & 4 & 5 \\
\hline Tricuspid valve replacement & 1 & 2 & 3 & 4 & 5 \\
\hline Pulmonary valve replacement & 1 & 2 & 3 & 4 & 5 \\
\hline \multicolumn{6}{|l|}{ Thoracic aortic disease } \\
\hline Axillary cannulation & 1 & 2 & 3 & 4 & 5 \\
\hline
\end{tabular}

TABLE 1. Continued

\begin{tabular}{lccccc}
\hline \multicolumn{1}{c}{ Skill } & Not necessary & Helpful & Essential \\
\hline Treatment of type A dissection & & & & & \\
$\quad$ AV resuspension & 1 & 2 & 3 & 4 & 5 \\
$\quad$ Interposition graft & 1 & 2 & 3 & 4 & 5 \\
$\quad$ Hemiarch & 1 & 2 & 3 & 4 & 5 \\
$\quad$ Total arch replacement & 1 & 2 & 3 & 4 & 5 \\
Treatment of type B dissection & & & & & \\
$\quad$ Open repair & 1 & 2 & 3 & 4 & 5 \\
$\quad$ Endovascular repair & 1 & 2 & 3 & 4 & 5 \\
Treatment of ascending thoracic & & & & & \\
$\quad$ aneurysm & 1 & 2 & 3 & 4 & 5 \\
$\quad$ Open repair & & & & & \\
Treatment of descending thoracic & & & & & \\
$\quad$ aneurysm & 1 & 2 & 3 & 4 & 5 \\
$\quad$ Open repair & 1 & 2 & 3 & 4 & 5 \\
$\quad$ Endovascular repair & & & & & \\
Surgery for arrhythmias & 1 & 2 & 3 & 4 & 5 \\
$\quad$ Surgery for atrial fibrillation & & & & & \\
Temporary mechanical support & & 2 & 3 & 4 & 5 \\
$\quad$ ECMO & 1 & 2 & 3 & 4 & 5 \\
$\quad$ LVAD & 1 & 2 & 3 & 4 & 5 \\
$\quad$ BiVAD & & & & & \\
Cardiac transplant & 1 & 2 & 3 & 4 & 5 \\
$\quad$ Donor harvest & 2 & 3 & 4 & 5 \\
$\quad$ Recipient implantation & 1 & & & \\
Resection of cardiac tumors & & & & \\
\hline
\end{tabular}

The residents and faculty were asked to complete the survey with the following instructions: "Below is a list of essential skills residents often acquire during cardiothoracic training. Please review each skill and determine the need for simulation training outside of the operating room. Based on these results we will establish the components of the cardiac simulation curriculum in the surgical skills training and simulation center. In the blank spaces provided, please list any additional procedural skills that you believe are important for residents to acquire during training." $C P B$, Cardiopulmonary bypass; IMA, internal mammary artery; VSD, ventricular septal defect; $A V R$, aortic valve replacement; $M V R$, mitral valve replacement; $A V$, aortic valve; $E C M O$, extracorporeal membranous oxygenation; $L V A D$, left ventricular assist device; $B i V A D$, biventricular assist device.

designated as instructors to teach the sessions. The sessions included a brief didactic presentation that addressed the cognitive elements of the skill, a demonstration of the surgical techniques by the instructor, and the opportunity for residents to practice at individual stations, ask questions, and receive feedback on their performance by the faculty. The most senior faculty was designated as the module instructor, and the remaining faculty supervised the individual task stations. Every resident was offered the opportunity for the deliberate practice of each skill until they were comfortable enough performing the procedure. After practice and feedback, each resident was required to demonstrate the skill back to the instructor. Residents with less than adequate performance were given remediation and additional practice until an acceptable level of skill acquisition was demonstrated.

\section{Evaluation}

Evaluation data were collected at the end of each module and consisted of satisfaction ratings, perceived competency scores, and pre- and postself-confidence ratings. The satisfaction assessment was an 8-item form consisting of specific questions reviewing the overall quality of the workshops on a 5-point Likert scale (1, strongly disagree to 5 , strongly agree) and 2 open-ended questions regarding strengths and areas for improvement. Perceived competency was assessed using a 10-point scale (1, strongly disagree to 10 , strongly agree). Each resident was asked to 
rate their ability to perform each procedure independently vs with supervision in the operating room. Finally, the self-confidence assessment used a pre- and postrating for each learning objective. A statistical analysis of the self-confidence scores was performed using a paired $t$-test on the combined data points for each module. Resident competency was determined subjectively at the end of each skill session in the simulation center when each resident was required to demonstrate the skill back to the instructor. The subjective evaluation was determined by whether each resident demonstrated competency of the objectives for each module. Residents who did not demonstrate the skill to the expectations of the faculty member were given the opportunity for additional practice and feedback and were re-assessed at a later time. The faculty rated the residents according to their own subjective determination of proficiency and were not asked to use any specific rating scale.

\section{RESULTS}

The scores from the needs assessment were organized according to the resident, faculty, and combined results and listed from highest to lowest (Table 2). To incorporate input from learners and instructors, procedures with a mean score of 4.0 or greater $(n=23)$ on the combined resident and faculty surveys were chosen for curriculum development. A subgroup of faculty members reviewed each individual procedure and grouped them into 13 modules based on similar themes (Table 3). It is important to note that the available facilities and resources did not permit adequate development of an endovascular simulation module. Therefore, 12 modules were chosen for curriculum implementation, and learning objectives were created for each module (Table 4).

The simulation tool chosen for each module is also listed in Table 3. Five modules were performed exclusively in the fresh tissue cadaver laboratory. Five modules were performed using a combination of porcine hearts and the high-fidelity trainer. One module used a combination of portable task trainers, a porcine heart preparation, and the high-fidelity trainer. Finally, 1 module used only the highfidelity trainer.

The cumulative average scores for each of the 8 items on the resident satisfaction assessment of the simulation modules is presented in Table 5 (scale 1, strongly disagree to 5, strongly agree). The resident responses to the skills workshops were overwhelmingly positive and quantitative data revealed high satisfaction with the curriculum. In addition to the information collected on the 5-point Likert scale, qualitative data were collected, and residents were asked to list the strengths and weaknesses of the sessions. Several themes emerged from the qualitative analysis. Overall, the residents believed the simulation laboratories were educational and realistic. They expressed an appreciation for the effort that the Department had invested in the curriculum. The suggestions for improvement included increasing the number of simulation sessions.

The perceived self-competency scores are presented in Table 6. "N" in Table 6 refers to the cumulative total of all resident responses related to all the learning objectives.
An analysis of the data revealed that the residents were overwhelmingly comfortable performing all the procedures with supervision. However, the residents were less comfortable performing each procedure independently. Specifically, the residents were least competent in performing minimally invasive valve surgery, mitral and tricuspid repair, left ventricular assist device placement, and aortic dissection (mean score $\leq 7$ ) independently.

Finally, the pre-and post-self-confidence scores for each module are presented in Table 7. The residents' self confidence/efficacy increased significantly after each session module $(P<.001)$. Anecdotally, the residents reported that they thought they were much better prepared to perform each skill in the operating room and expressed gratitude for the opportunity to practice.

\section{DISCUSSION}

Simulation is an increasingly vital component of graduate medical education and is becoming the standard of practice in many residency programs, ${ }^{13}$ especially in the surgical specialties owing to the need, "to move basic skills acquisition out of the operating room and into the surgical skills laboratories." ${ }^{, 7}$ Deliberate practice is an educational technique aimed at improving performance by intense training and preparation. These steps include repetition, assessment, and feedback, which lead to performance improvement. ${ }^{4}$ Okuda and colleagues ${ }^{3}$ reported the enhancement of medical education when the principles of deliberate practice are applied in simulation-based teaching. These concepts have tremendous potential in the field of CT surgery in which, the traditional apprenticeship model "suffers from poor reliability when applied to performance assessment and teaching." 3

To date, early, but instrumental, work has been done to develop cardiac simulation models. ${ }^{5-8}$ However, great variability exists in the fidelity, technology, and costs of these various simulation methods. Given the current financial constraints of most residency training programs, a need exists to develop simulation curricula using costeffective high-fidelity tools. This will require novel approaches as exemplified by Schiralli and colleagues. ${ }^{8}$ In anticipation of the challenges associated with the younger learners in the integrated CT training program, the Joint Council of Thoracic Surgery Education is directing efforts toward creating a national technical skills curriculum.

The present report describes our experience in developing a focused simulation curriculum and its implementation in a traditional CT training program. The results of this project have implications for $\mathrm{CT}$ educators who are exploring methods to improve resident training in CT surgery. This pilot project was an initial attempt to teach and assess surgical skills in a simulated environment using a structured approach. It is well known by educational psychologists that a formal approach to curriculum development is important 
TABLE 2. Mean scores from faculty, resident, and combined responses

\begin{tabular}{|c|c|c|c|c|c|}
\hline Faculty & Score & Residents & Score & Combined responses* & Score \\
\hline Mitral valve replacement & 4.56 & Beating heart coronary anastomosis & 5.00 & Beating heart coronary anastomosis & 4.60 \\
\hline Mitral valve posterior leaflet repair & 4.56 & Management of small aortic root & 4.83 & Aortic root replacement & 4.60 \\
\hline $\begin{array}{l}\text { Descending thoracic aneurysm } \\
\text { endovascular repair }\end{array}$ & 4.56 & Aortic root replacement & 4.83 & Mitral valve replacement & 4.60 \\
\hline Aortic root replacement & 4.44 & Valve sparing aortic root replacement & 4.67 & Mitral valve posterior leaflet repair & 4.60 \\
\hline Redo sternotomy & 4.33 & Mitral valve replacement & 4.67 & Management of small aortic root & 4.53 \\
\hline Coronary artery anastomosis & 4.33 & Mitral valve posterior leaflet repair & 4.67 & Redo sternotomy & 4.40 \\
\hline Beating heart coronary anastomosis & 4.33 & Mitral valve anterior leaflet repair & 4.67 & Coronary artery anastomosis & 4.40 \\
\hline Aortic valve replacement & 4.33 & Redo sternotomy & 4.50 & Type B dissection endovascular repair & 4.33 \\
\hline Management of small aortic root & 4.33 & Coronary artery anastomosis & 4.50 & Mitral valve anterior leaflet repair & 4.29 \\
\hline IMA harvest & 4.22 & Aortic homograft & 4.50 & Surgery for atrial fibrillation & 4.27 \\
\hline Tricuspid valve repair & 4.22 & Total arch replacement & 4.50 & Aortic valve replacement & 4.20 \\
\hline Type B dissection endovascular repair & 4.22 & Type B dissection endovascular repair & 4.50 & Tricuspid valve repair & 4.20 \\
\hline Surgery for atrial fibrillation & 4.22 & Weaning from $\mathrm{CPB}$ & 4.33 & $\begin{array}{l}\text { Descending thoracic aneurysm } \\
\text { endovascular repair }\end{array}$ & 4.20 \\
\hline Axillary cannulation & 4.11 & Ross procedure & 4.33 & Weaning from $\mathrm{CPB}$ & 4.13 \\
\hline Weaning from $\mathrm{CPB}$ & 4.00 & Minimally invasive AVR & 4.33 & Aortic homograft & 4.13 \\
\hline Endoscopic saphenous vein harvest & 4.00 & Minimally invasive MVR & 4.33 & Valve sparing aortic root replacement & 4.13 \\
\hline Mitral valve anterior leaflet repair & 4.00 & $\mathrm{AV}$ resuspension & 4.33 & Minimally invasive MVR & 4.13 \\
\hline Minimally invasive MVR & 4.00 & Surgery for atrial fibrillation & 4.33 & Minimally invasive AVR & 4.13 \\
\hline Minimally invasive AVR & 4.00 & Repair of postinfarct VSD & 4.17 & $\mathrm{AV}$ resuspension & 4.07 \\
\hline Proximal anastomosis & 3.89 & Tricuspid valve repair & 4.17 & Total arch replacement & 4.07 \\
\hline Aortic homograft & 3.89 & Pulmonary valve replacement & 4.17 & Endoscopic saphenous vein harvest & 4.00 \\
\hline AV resuspension & 3.89 & LVAD & 4.17 & IMA harvest & 4.00 \\
\hline LVAD & 3.89 & Donor harvest & 4.17 & LVAD & 4.00 \\
\hline Open radial artery harvest & 3.78 & Recipient implantation & 4.17 & Repair of postinfarct VSD & 3.87 \\
\hline Valve sparing aortic root replacement & 3.78 & Coronary sinus catheterization & 4.00 & Hemiarch & 3.87 \\
\hline Hemiarch & 3.78 & Beginning $\mathrm{CPB}$ & 4.00 & Coronary sinus catheterization & 3.86 \\
\hline Total arch replacement & 3.78 & Endoscopic saphenous vein harvest & 4.00 & Axillary cannulation & 3.80 \\
\hline Ascending thoracic aneurysm open repair & 3.78 & Aortic valve replacement & 4.00 & Recipient implantation & 3.80 \\
\hline Coronary sinus catheterization & 3.75 & Tricuspid valve replacement & 4.00 & Donor harvest & 3.67 \\
\hline Repair of postinfarct VSD & 3.67 & Hemiarch & 4.00 & Tricuspid valve replacement & 3.64 \\
\hline Interposition graft & 3.67 & Aortic cannulation & 3.83 & Aortic cannulation & 3.60 \\
\hline Femoral cannulation/decannulation & 3.56 & Endoscopic radial artery harvest & 3.83 & Beginning $\mathrm{CPB}$ & 3.60 \\
\hline Descending thoracic aneurysm open repair & 3.56 & Placement of vent & 3.67 & Ascending thoracic aneurysm open repair & 3.60 \\
\hline ECMO & 3.56 & IMA harvest & 3.67 & Ross procedure & 3.53 \\
\hline BiVAD & 3.56 & Minimally invasive direct $\mathrm{CAB}$ & 3.67 & Interposition graft & 3.53 \\
\hline Recipient implantation & 3.56 & $\begin{array}{l}\text { Descending thoracic aneurysm } \\
\text { endovascular repair }\end{array}$ & 3.67 & BiVAD & 3.53 \\
\hline Aortic cannulation & 3.44 & Venous cannulation & 3.50 & Femoral cannulation/decannulation & 3.47 \\
\hline Open saphenous vein harvest & 3.44 & Transmyocardial revascularization & 3.50 & Proximal anastomosis & 3.47 \\
\hline Type B dissection open repair & 3.44 & Type B dissection open repair & 3.50 & Type B dissection open repair & 3.47 \\
\hline Tricuspid valve replacement & 3.38 & BiVAD & 3.50 & ECMO & 3.47 \\
\hline Beginning CPB & 3.33 & Cardioplegia cannula placement & 3.33 & Open radial artery harvest & 3.40 \\
\hline Donor harvest & 3.33 & Femoral cannulation/decannulation & 3.33 & Descending thoracic aneurysm open repair & 3.40 \\
\hline Intra-aortic balloon pump placement & 3.22 & Axillary cannulation & 3.33 & Placement of vent & 3.33 \\
\hline Median sternotomy & 3.11 & Interposition graft & 3.33 & Minimally invasive direct $\mathrm{CAB}$ & 3.33 \\
\hline Venous cannulation & 3.11 & Ascending thoracic aneurysm open repair & 3.33 & Venous cannulation & 3.27 \\
\hline Cardioplegia cannula placement & 3.11 & ECMO & 3.33 & Pulmonary valve replacement & 3.27 \\
\hline Placement of vent & 3.11 & Descending thoracic aneurysm open repair & 3.17 & Cardioplegia cannula placement & 3.20 \\
\hline Minimally invasive direct $\mathrm{CAB}$ & 3.11 & Resection of cardiac tumors & 3.00 & Open saphenous vein harvest & 3.07 \\
\hline Ross procedure & 3.00 & Open radial artery harvest & 2.83 & Endoscopic radial artery harvest & 2.93 \\
\hline Pericardial window & 2.75 & Proximal anastomosis & 2.83 & Transmyocardial revascularization & 2.93 \\
\hline Pulmonary valve replacement & 2.67 & Open saphenous vein harvest & 2.50 & Resection of cardiac tumors & 2.79 \\
\hline Resection of cardiac tumors & 2.67 & Pericardial window & 2.17 & Intra-aortic balloon pump placement & 2.60 \\
\hline
\end{tabular}


TABLE 2. Continued

\begin{tabular}{lccccc}
\hline \multicolumn{1}{c}{ Faculty } & Score & Residents & Score & Combined responses* & Score \\
\hline Transmyocardial revascularization & 2.56 & Median sternotomy & 1.67 Median sternotomy & 2.53 \\
Endoscopic radial artery harvest & 2.33 & Intra-aortic balloon pump placement & 1.67 Pericardial window & 1.67 \\
\hline
\end{tabular}

$I M A$, Internal mammary artery; $C P B$, cardiopulmonary bypass; $A V R$, aortic valve replacement; $M V R$, mitral valve replacement; $A V$, aortic valve; $V S D$, ventricular septal defect; $L V A D$, left ventricular assist device; $E C M O$, extracorporeal membranous oxygenation; $B i V A D$, biventricular assist device; $C A B$, coronary artery bypass. *The 23 highest scoring procedures, corresponding to a mean score of $\geq 4$, were chosen for curriculum development.

to provide learners with a comprehensive learning experience and promote mastery of content; however, surgical programs are slow to apply this method, and many programs do not have an explicit and structured skills curriculum. One of the initial steps in developing a curriculum is to perform a needs assessment to identify the gaps in training and determine the specific needs of individual programs. This information is used to guide curricular efforts and is an important step in curriculum development. The goal of this project was to determine the feasibility of creating a simulation curriculum at our institution. These survey results reflect the need of 1 individual program and might not be applicable to other programs with varying faculty expertise and disease prevalence. However, for skill simulation centers to provide the most benefit to learners, the curriculum needs to be focused on the needs of each program. In this project, we were able to apply the 6 steps of curriculum development to develop and implement a cardiac surgery skills curriculum and afford the residents the opportunity for deliberate practice.

One of the challenges to creating a simulation curriculum is determining which skills are the most essential to include. From the results of our needs assessment, we were able to determine the skills deemed the most important by the faculty and residents and created 12 independent modules, which included the 23 highest scoring procedures. The modules were performed using a variety of simulation tools, including inanimate, animate, and cadaveric, and a highfidelity trainer.

We acknowledge that the availability of an established fresh tissue cadaveric program at USC greatly enhanced our ability to implement our simulation curriculum. This facility was established at LAC+USC Medical Center in 2006 for the purpose of surgical education. Fresh tissue dissection allows for realistic technical surgical experience and demonstration of actual surgical procedures. This is in distinction from the "fully embalmed" cadavers used in medical school curricula. The cadavers used in the laboratory are received in the frozen, unembalmed state. Our simulation modules were performed using thawed "fresh," unembalmed cadavers. This experience provided a novel and incredibly effective method of simulation and might prove to be the best medium for "deliberate practice" of many essential cardiac skills, such as redo sternotomy and internal mammary artery harvest. The process of "light embalming" offers temporary, life-like preservation of the tissues for at least 6 weeks, thereby allowing multiple uses. ${ }^{12}$ Other programs should be encouraged to investigate the feasibility of a similar arrangement at their respective institutions. This would provide an economic advantage for training programs, which have a cost associated with obtaining cadaveric models.

TABLE 3. Simulation modules and tools

\begin{tabular}{llll}
\hline Module & \multicolumn{1}{c}{ Topic } & \multicolumn{1}{c}{ Procedure skills } & Simulation tool \\
\hline 1 & Anastomosis & Coronary artery anastomosis; beating heart anastomosis & $\begin{array}{c}\text { Portable task trainers, porcine heart and } \\
\text { high-fidelity trainer } \\
\end{array}$ \\
& Basic skills & Redo sternotomy; IMA harvest & $\begin{array}{c}\text { Fresh tissue cadaver } \\
\text { Porcine heart, high-fidelity trainer }\end{array}$ \\
3 & Aortic valve & AVR; management of small aortic root & Porcine heart, high-fidelity trainer \\
4 & MV/atrial fibrillation & MVR; surgical management of atrial fibrillation & Porcine heart, high-fidelity trainer \\
5 & Mitral and tricuspid repair & MV posterior leaflet repair; MV anterior leaflet & Fresh tissue cadaver \\
& & repair; TV repair & Fresh tissue cadaver \\
6 & Aortic dissection & AV resuspension; total arch replacement & Porcine heart, high-fidelity trainer \\
7 & Minimally invasive valve surgery & Minimally invasive MVR; minimally Invasive AVR & Porcine heart, high-fidelity trainer \\
8 & Aortic root replacement & Root replacement; homograft & Fresh tissue cadaver \\
9 & Valve sparing root & Valve sparing aortic root replacement & Fresh tissue cadaver \\
10 & Vein harvest & Endoscopic saphenous vein harvest & High-fidelity trainer \\
11 & LVAD & LVAD Placement & NA \\
12 & CPB & Weaning from CPB & Type B dissection; endovascular repair; descending
\end{tabular}

$I M A$, Internal mammary artery; $A V R$, aortic valve replacement; $M V$, mitral valve; $M V R$, mitral valve replacement; $T V$, tricuspid valve; $A V$, aortic valve; $L V A D$, left ventricular assist device; $C P B$, cardiopulmonary bypass; $N A$, not available. *Module not conducted. 


\section{TABLE 4. Learning objectives}

Module 1 -anastomosis (coronary artery anastomosis, beating heart anastomosis)

Ability to perform coronary anastomosis*

Module 2-basic skills (redo sternotomy, IMA harvest)

Understand anatomy of the sternum

Identification of midline

Understanding complications of sternotomy

Comfort with application of redo saw

Understand anatomy of IMA

Understand methods of IMA harvest

Understand pedicle vs skeletonized techniques

Understand proximal and distant extent of dissection

Ability to perform IMA harvest

Module 3-aortic valve (AVR, management of small aortic root)

Understand implications of small aortic root

Delineate aortic root anatomy

Ability to compute acceptable minimal size prosthesis

Comprehend options for management of small aortic root

Ability to perform aortic root enlargement procedure

Pledget alignment

Suture placement

Comprehend valve geometry

Understand prosthetic valve design

Module 4-MVR/atrial fibrillation (MVR, surgical management of atrial fibrillation)

Delineate mitral valve anatomy

Comprehend valve geometry

Understand biatrial, dome, and transeptal approaches

Pledget alignment

Suture placement

Location of lesion sets

Module 5-mitral and tricuspid repair (MV posterior leaflet repair, MV anterior leaflet repair, TV repair)

Understand anatomy of MV

Understand various repair options of anterior and posterior leaflets

Ability to perform posterior annuloplasty

Ability to perform quadrangular resection

Understanding anatomy of TV

Ability to perform tricuspid annuloplasty

Module 6-aortic dissection (AV resuspension, total arch replacement)

Comfort with axillary cannulation

Understand technique of AV resuspension

Understand surgical anatomy of aortic arch

Ability to perform aortic arch anastomosis using open distal technique

Understand technique and indications for total arch replacement

Module 7-minimally invasive valve surgery (minimally invasive MVR, minimally invasive AVR)

Appropriate placement of incision and selection for entering space for MVR and AVR

Achieve adequate exposure by way of minimally invasive incision

Understand indications for central vs peripheral cannulation

Achieve adequate exposure of MV

Achieve adequate exposure of AV

Ability to use minimally invasive instruments to perform MVR and AVR

Module 8-aortic root replacement (root replacement, homograft)

Understand aortic root anatomy

(Continued)
TABLE 4. Continued

Understand indications for aortic homograft

Understand technique of aortic homograft root replacement, including selecting appropriately sized homograft

Ability to perform aortic homograft

Module 9-valve sparing root (valve sparing aortic root replacement)

Understand aortic root anatomy as it relates to valve sparing technique

Understand indications for valve sparing aortic root replacement

Understand technique of valve sparing aortic root replacement, including selecting appropriate graft size

Ability to dissect and prepare aortic root

Ability to perform valve sparing aortic root replacement

Module 10-vein harvest

Understand components of equipment for endoscopic vein harvest

Understand vein identification

Understand endoscopic vein harvesting technique

Ability to identify and ligate saphenous vein branches

Understand indications for conversion to open technique

Module 11-LVAD

Understand indications for LVAD

Understand different devices available and device mechanisms

Understand technique of LVAD insertion

Understand implantation of LV apical cannula

Understand placement and technique of aortic outflow graft

Module 12-CPB

Comprehension of CPB circuit

Understand weaning bypass physiology

Pitfalls/complications associated with CPB

Ability to resolve CPB issues

$I M A$, Internal mammary artery; $A V R$, aortic valve replacement; $M V R$, mitral valve replacement; $M V$, mitral valve; $T V$, tricuspid valve; $A V$, aortic valve; $L V A D$, left ventricular assist device; $L V$, left ventricle; $C P B$, cardiopulmonary bypass. *Detailed learning objectives not established for module 1 .

Another significant finding in the present study was the residents' self-confidence ratings, which increased significantly after the sessions. These findings support those found in the published data ${ }^{14,15}$ that providing structured teaching sessions improves the confidence level of learners. Selfconfidence has been shown to effect learner motivation and performance achievement. ${ }^{16}$ According to Bandura, ${ }^{16,17}$ a learner's behavior is often predicted by their beliefs about their own capabilities, and those with greater self-confidence for accomplishing a task participate more readily, work harder, and persist longer when they encounter a problem. Learners who have had the opportunity for deliberate practice of skills in an inanimate setting have been shown to have increased levels of confidence and decreased levels of anxiety when performing skills in the clinical setting. ${ }^{15}$ In addition, residents reported that they felt more prepared and less anxious for operative cases.

Some limitations were associated with our cardiac surgery simulation curriculum development and implementation. Anastomosis was our first module implemented, and we did not have detailed learning objectives developed for evaluation at that time. In addition, owing to the inherent 
TABLE 5. Summary of resident satisfaction scores for CT simulation modules $(\mathbf{n}=\mathbf{5 7})$

\begin{tabular}{lc}
\hline \multicolumn{1}{c}{ Question } & Score \\
\hline Course content was appropriate to my level of learning. & 4.8 \\
Course content was delivered in an efficient manner. & 4.8 \\
Instructor(s) was enthusiastic about the topic. & 5.0 \\
Instructor(s) was knowledgeable in the field. & 4.9 \\
Skill station(s) were favorable to learning. & 4.9 \\
I had enough time for practice during the skills station(s). & 4.7 \\
Overall, I was satisfied with the course. & 4.9 \\
This course should be taught again. & 5.0 \\
\hline Scale: 1 , strongly disagree; 2 , disagree; 3 , neutral; 4, agree; 5, strongly agree.
\end{tabular}

financial limitations of purchasing a high-fidelity endovascular simulator, we were not able to simulate endovascular repairs of type $\mathrm{B}$ dissections and descending thoracic aneurysms. Therefore, 12 modules were implemented monthly into our existing education curriculum.

It is important to recognize that the present study was designed to bridge the curricular gap in the CT program within our own institution; therefore, the survey results reflect the needs of 1 specific program. It should be assumed that each program will have a slightly different patient population and focus; therefore, each curriculum should be tailored to meet the needs of the respective institution. Our hope is that the present project serves as a guide to assist other programs with the formal curriculum development process. In addition, the small number of learners restrained our capacity to gather psychometrically sound data for curriculum validation. The module instructors also varied in their level of experience.

Another limitation in the present project was that there might have been some bias in the residents' evaluation of

TABLE 6. Perceived resident competency

\begin{tabular}{llcc}
\hline & & \multicolumn{2}{c}{ Cumulative mean score } \\
\cline { 3 - 4 } Module & \multicolumn{1}{c}{$\begin{array}{c}\text { Topic } \\
\text { (data points*) }\end{array}$} & $\begin{array}{c}\text { Competent to } \\
\text { perform with } \\
\text { supervision }\end{array}$ & $\begin{array}{c}\text { Competent } \\
\text { to perform } \\
\text { independently }\end{array}$ \\
\hline 1 & Anastomosis $\dagger$ & NA & NA \\
2 & Basic skills (41) & 9.49 & 8.18 \\
3 & Aortic valve (41) & 9.15 & 7.17 \\
4 & MVR/Atrial fibrillation (23) & 9.21 & 7.17 \\
5 & MV and TV repair (30) & 8.83 & 6.7 \\
6 & Aortic dissection (16) & 8.41 & 6.76 \\
7 & Minimally invasive & 8.8 & 6.48 \\
& valve surgery (25) & & 7.31 \\
8 & Aortic root & 9.25 & 7.12 \\
9 & replacement (16) & & 7.60 \\
10 & Valve sparing root (25) & 9.00 & 6.72 \\
12 & Vein harvest (25) & 9.28 & 7.00 \\
\hline & LVAD (25) & 8.64 & 9.45 \\
\hline
\end{tabular}

Scale: 1 , completely disagree; 10 , completely agree. $N A$, Not available; $M V R$, mitral valve replacement; $M V$, mitral valve; $T V$, tricuspid valve; $L V A D$, left ventricular assist device; $C P B$, cardiopulmonary bypass. *Number of data points determined from total responses for each module. †Formal assessment not performed for module 1.
TABLE 7. Resident self-confidence before and after simulation modules

\begin{tabular}{llcc}
\hline & & \multicolumn{2}{c}{ Cumulative mean score } \\
\cline { 3 - 4 } Module & \multicolumn{1}{c}{ Topic (data points*) } & Before module & After module \\
\hline 1 & Anastomosis $\dagger$ & NA & NA \\
2 & Basic skills (41) & $4 \pm 0.12$ & $4.8 \pm 0.07$ \\
3 & Aortic valve (41) & $3.24 \pm 0.16$ & $4.59 \pm 0.09$ \\
4 & MVR/atrial fibrillation (23) & $2.91 \pm 0.17$ & $4.26 \pm 0.09$ \\
5 & MV and TV repair (30) & $3.23 \pm 0.11$ & $4.33 \pm 0.12$ \\
6 & Aortic dissection (16) & $3.81 \pm 0.16$ & $4.69 \pm 0.12$ \\
7 & Minimally invasive valve & $3.44 \pm 0.10$ & $4.76 \pm 0.10$ \\
& $\quad$ surgery (25) & & \\
8 & Aortic root replacement (16) & $3.44 \pm 0.16$ & $4.63 \pm 0.13$ \\
9 & Valve sparing root (25) & $3.64 \pm 0.17$ & $4.44 \pm 0.10$ \\
10 & Vein harvest (25) & $4.04 \pm 0.07$ & $4.88 \pm 0.07$ \\
11 & LVAD (25) & $3.4 \pm 0.10$ & $4.72 \pm 0.11$ \\
12 & CPB (20) & $3.6 \pm 0.21$ & $4.5 \pm 0.14$ \\
\hline
\end{tabular}

Data presented as mean \pm standard error of the mean. Paired $t$-test performed for scores before and after module sessions; for all comparisons, $P<.001$. NA, Not available; $M V R$, mitral valve replacement; $M V$, mitral valve; $T V$, tricuspid valve; $L V A D$, left ventricular assist device; $C P B$, cardiopulmonary bypass. *Number of data points determined by total responses for each module. $\dagger$ Formal assessment not performed for module 1 .

satisfaction and goal achievement owing to the small number of trainees and educators. It is possible that the trainees had some difficulty in objectively evaluating a program designed specifically for them by their own faculty. In an attempt to minimize this, we were sincere when we told them their honest feedback was essential to evaluate and improve the program.

Finally, the focus of the present study was the assessment of the curriculum and not to establishing a competencybased evaluation system for the residents. In this project, learners were assessed subjectively at the end of each session and asked to demonstrate the skill back to the instructor. The residents who did not perform the skill adequately were given remediation and the opportunity to "re-test" at a later time. Future research projects should focus on establishing standard proficiency levels and the development of formal evaluation tools for resident performance. Increasing national attention is currently being directed at establishing formal evaluation tools for resident performance and will need to be included in future protocols.

\section{Maintenance}

We plan on continuing and improving the simulation modules established during this pilot year as a formal part of the cardiac surgery educational curriculum and incorporate multidisciplinary crisis management training. In anticipation of younger and less experienced residents, we plan to implement weekly modules to enhance overall resident training and performance. Focused groups with current residents directed at revising the current simulation modules to identify any gaps will also be performed. Information 
obtained from these sessions will be used to revise and enhance the curriculum. In addition, we will re-evaluate the results of our current needs assessment and anticipate performing future needs assessment to delineate the importance of incorporating different modules in the future. Although the present study did not use specific evaluation tools of learner performance, national efforts are currently underway to develop formal assessments of resident performance. This will be an important adjunct to future simulation protocols.

\section{CONCLUSIONS}

A pressing need exists to incorporate simulation-based training into existing and future CT surgery residency programs. As mandates for quality measures and shorter training periods emerge, teaching alone using the traditional "apprenticeship" model in the operating room will no longer be sufficient. We have shown that it is feasible to develop and implement a cardiac surgery simulation curriculum using a structured approach. High-fidelity, low-technology tools such as a fresh tissue cadaver laboratory and a virtual operating room might be important adjuncts to successful curriculum implementation. In the present report, our goal was to provide a framework for a formal curriculum development process that can be used by other programs when developing individualized simulation curricula. Each program should recognize that a needs assessment can help focus the curricular content and that implementation will vary depending on resources, faculty time, and available educational time. Individual programs could benefit from defining specific needs, which will be important for the widespread and local implementation of simulation-based training in CT surgery.

\section{References}

1. Raemer DB. Simulation in cardiothoracic surgery: a paradigm shift in education? J Thorac Cardiovasc Surg. 2009;138:1065-6.

2. Grover A, Gorman KR, Dall TM, Jonas R, Lytle B, Shemin R, et al. Shortage of cardiothoracic surgeons is likely by 2020. Circulation. 2009;120:488-94.

3. Okuda Y, Bryson EO, DeMaria S, Jacobson L, Quinones J, Shen B, et al. The utility of simulation in medical education: what is the evidence? Mt Sinai J Med. 2009;76:330-43.

4. Ericsson KA. Deliberate practice and acquisition of expert performance in medicine and related domains. Acad Med. 2004;79(Suppl):S70-81.

5. Fann JI, Calhoon JH, Carpenter AJ, Merrill WH, Brown JW, Poston RS, et al. Simulation in coronary artery anastomosis early in cardiothoracic surgical residency training: the Boot Camp experience. J Thorac Cardiovasc Surg. 2010;139: 1275-81.

6. Fann JI, Caffarelli AD, Georgette G, Howard SK, Gaba DM, Younglood P, et al. Improvement in coronary anastomosis with cardiac surgery simulation. J Thorac Cardiovasc Surg. 2008;136:1486-91.

7. Ramphal PS, Coore DN, Craven MP, Forbes NF, Newman SM, Coye AA, et al. A high fidelity tissue-based cardiac surgical simulator. Eur J Cardiothorac Surg. 2005;27:910-6.

8. Schiralli MP, Hicks GL, Angona RE, Gangemi JJ. An inexpensive cardiac bypass cannulation simulator: facing challenges of modern training. Ann Thorac Surg. 2010;89:2056-7.

9. Halkos ME, Puskas JD. Teaching off-pump coronary artery bypass surgery. Semin Thorac Cardiovasc Surg. 2009;21:224-8.
10. Feins RH. Expert commentary: cardiothoracic surgical simulation. J Thorac Cardiovasc Surg. 2008;135:485-6.

11. Kern DE, Thomas PA, Howard DM, Bass EB. Curriculum Development for Medical Education: A Six Step Approach. Baltimore, MD: John Hopkins University Press; 1998

12. Anderson SD. Practical light embalming technique for use in the surgical fresh tissue dissection laboratory. Clin Anat. 2006;19:8-11

13. Chipman JG, Acton RD, Schmitz CC. Developing surgical skills curricula: lessons learned from needs assessment to program evaluation. J Surg Educ. 2009; 66:133-9.

14. Peyre SE, Peyre CG, Sullivan ME, Towfigh S. A surgical skills elective can improve student confidence prior to internship. J Surg Res. 2006;133:11-5.

15. Stewart RA, Hauge LS, Stewart RD, Rosen RL, Katsikas AC, Prinz RA. A CRASH course in procedural skills improves medical students' self-assessment of proficiency, confidence and anxiety. Am J Surg. 2007;193:771-3.

16. Bandura A. Self-efficacy: The exercise of control. New York: WH Freeman 1997.

17. Bandura A. Social foundations of thought and action. Englewood Cliffs, NJ: Prentice-Hall; 1986.

\section{Discussion}

Dr James Fann (Stanford, Calif). Dr Sinha, I want to congratulate you and your colleagues on a highly informative presentation.

Surgical training traditionally has been based on an apprenticeship model with the predominance of technical training in the operating room; however, the operating room may not be the ideal place for early surgical training because of the issues you discussed. Although simulation-based training, if done properly, can provide needed training and practice outside the operating room, the adoption of simulation training has not been as widespread among cardiothoracic surgical educators. The situation is improving particularly with the efforts of the Joint Council, TSDA, ABTS, TSFRE, and the discussions here at the Western Thoracic Surgical Association.

You and your group have approached simulation in a systematic way, starting with needs assessment and defining the goals and objectives. Based on your needs assessment, members of the faculty identified, in order of importance, mitral valve surgery, thoracic aortic surgery, aortic root replacement, and coronary anastomosis, taking into consideration the complexity and frequency of these procedures in the clinical setting. What is interesting is that the residents emphasized in rank order the importance of beating-heart surgery, management of the small aortic root, aortic root replacement including valve-sparing approach, and mitral valve procedures. The differences in the order of perceived need between the 2 groups may reflect the level of comfort that the resident has and the level of faculty comfort in resident training. So the needs assessment has effectively defined for us the subtle but real differences in what residents think they need to know and what faculty think they need to know. Thus, what I consider to be a communiqué from the residents to the educators has important implications in developing better teaching tools.

How have these findings regarding needs assessment impacted the approach of the faculty in resident training in the simulation laboratory and in the clinical setting? Do you think that the laboratory skills are transferable to the operating room?

Dr Sinha. Thank you very much, Dr Fann, for that excellent question. Of course, transferability of these learned procedures is of utmost importance for all residents. Although we do not 
have quantitative data for this, we have noted that, after several of the simulation labs, for example, mitral and tricuspid repairs, have become easier for the residents to perform at our county facility and faculty have noticed an improvement.

Dr Fann. The development of 12-13 modules including synthetic, tissue-based, and fresh cadaveric models is labor and resource intensive, and I am appreciative of your team in assembling all of these. From the standpoint of the basic simulation laboratory, based on your experience with these modules, what would you tell someone who is starting a simulation laboratory what the critical simulators are?

Dr Sinha. That is also a very important point. First we need to keep in mind the learners in the simulation lab. Our learners were traditional graduates of general surgery residency programs and, therefore, were technically more advanced than, for example, a beginner in an integrated 6-year program, so depending on the level of the learner, different simulation tools can be used, such as the portable task trainers. For example, the anastomosis module could be of use to a younger learner; however, for our more trained residents, we felt that was better performed in a porcine heart model. Depending on the availability of the resources for each program as well as the level of the learner's experience, they should be able to tailor the tools accordingly.

Dr Fann. And the final question. The educational methods presented comprise one area that all educators would find very interesting, that is, determining the appropriate representative modalities or simulators. Although trainee perception of satisfaction and perceived competency and self-confidence are well described and satisfy the concept of face validity, what I am concerned about is how one can carry this forward to the use for remediation and formative assessment, and potentially high-stakes, proficiencybased advancement. Developing the simulators and assessing their utility and to the extent possible their validity are of paramount importance. What are your thoughts about the natural extension of this simulation for the use of formative and summative assessment and also how have the faculty been educated in terms of providing formative assessment?

Again, I thoroughly enjoyed the presentation and look forward to further insights from you and your colleagues, and I thank the Association for the privilege of discussing this paper.

Dr Sinha. Thank you. Again, 2 important points there. Using this information to go forward is of importance; however, at this point, simulation is still in its infancy period in cardiothoracic training, so we can extrapolate data from this to be able to develop objective learner tools to establish proficiency as well as transferability to patient care in the operating room. I think that is going to take some time but that is the eventual goal.

In addition, as far as teaching the learners evaluation skills, that is another important component of evaluation of overall curriculum as well as faculty education, and that is something that we are working on with our PhD educator, Dr Sullivan, to help expand on to make sure that things such as cognitive task analysis are incorporated so that educators are really aware of how they are able to give assessment based on what they are teaching. 